\title{
Diet and disease in East and West Germany
}

\author{
BY LENORE KOHLMEIER AND REINHARD DORTSCHY \\ Institute for Social Medicine and Epidemiology, Federal Health Office, Berlin, Germany
}

\section{INTRODUCTION}

The eyes of the world are on Germany these days, and have been since November 1989 , not only because of concern about the potential power that lies behind a country of 80 million persons, and not just because of the fear born of two world wars fought on this continent, nor due to concern that Germany has the resources, know-how and potential to dominate on the economic front. There is also a natural curiosity, like that which led to the studies of monozygous twins brought up separately, to know what happens when a genetically similar pcople are artificially and randomly divided, living under different conditions for 28 years. This is the natural experiment we are attempting to carry out through epidemiological research. This situation has led, naturally, to two sets of questions about the consequences of these exposures. The first set refers to whether measurable changes have developed during this time-period, and if so, how extensive and how lasting are they? The second set can only be answered in the future: how rapidly will the situation equalize in both parts of Germany, in which direction does the future health picture lie for Germany as a whole, more favourable or less favourable than currently experienced in the former West Germany, or as a weighted average of both parts, and which factors will be causal in any changes which now come about in the former East German states?

A third, more important question has arisen in the meantime; we are beginning to ask if the fall of the wall was like Eve biting into the apple. Did it mean banishment from a Garden of Eden in which everyone had equal access to adequate amounts of food, education and health care? Were people happier than they are now?

We have come a long way since the euphoria of 9 November 1989 . Currently, it must be acknowledged that the destabilizing insecurities are not contributing to the health and well-being of the former East Germans. They are now faced with job insecurity, or more precisely, unemployment, fear of losing their homes due to old claims dating back half a century, and loss of social support systems in the form of day care for children. Sport clubs which were free and readily accessible are disappearing. The quality of life, in many measurable dimensions, has worsened. This is reflected in the sudden drop in birth rates.

The current strategy of the World Health Organization is stimulating the creation of 'supportive environments' as outlined in the statement of the Sundsvall Conference held in Sweden this June (World Health Organization/UNEP, 1991). Four arcas have been identified as being focal in supportive environments: housing, transportation, education and food. We have need to examine how supportive our environments (in the broadest sense of the word) are and how they contribute to the health of our populations and the very different experiences of East and West Germany provide fertile ground for comparison. Of the four previously mentioned aspects of environment, food has changed most drastically in East Germany since the fall of the wall. No scientist would doubt that 
nutrition has played an important role in the differential in health status between the two parts of Germany.

HEALTH STATUS IN THE OLD AND NEW GERMAN STATES: THE NEED FOR BETTER INFORMATION

Returning to the question of whether health status differed between East and West Germany before the fall of the wall, it becomes clear that a complete answer to this question would require more and better information than is available currently.

Comparability of mortality data depends on comparable death certificate coding practices (Percy \& Muir, 1989) and uncensored documentation of the information acquired. The comparison of incidence figures for cancer, diabetes mellitus and other diseases depends also on comparable diagnoses, the coverage of representative or comparable samples of the respective populations, and similar times of diagnoses (Muir et al. 1987). Biochemical indicators and anthropometric measures need to be based on the same methodology, without systematic error between both countries or differential biases.

Food intake must also be assessed objectively using comparable sources of information and similar methods for coding and grouping foods (Arab, 1988), similar algorithms for estimating waste and distribution among individuals (Flores \& Nelson, 1988) and the comparable food-nutrient composition data must underlie the calculations of nutrient availability or intake (Paul \& Southgate, 1988; West, 1985). All this, of course, must also be in similar and comparable populations.

We have only mosaic pieces, which we can examine individually and try to piece together a picture of the physical and mental health of the two populations. A closer examination is not possible without comparable surveillance tools in a random sample of the population. This deficit will only be made good with the initiation of national and European health and nutrition surveillance systems.

Surveillance is needed for international comparisons, identification of unfavourable national trends, risk-group analyses, predictions of future morbidity and mortality and evaluation of policy effectiveness. The levels of information used for comparing both former countries are structured after the recommendations on nutrition surveillance of the IUNS Committee on Nutritional Surveillance and Program Evaluation (Kohlmeier et al. 1990). They include life expectancy, years of life lost, diseases contributing to premature mortality, risk factor status, eating behaviour, and knowledge.

\section{LIFE EXPECTANCY}

Life expectancy has been increasing steadily since the turn of the century. A comparison of the time trends reveals a scissoring in life expectancy in the 1970 s between the two Germanys. The life expectancy from birth in East Germany in 1989 was 76.4 years for women and $70 \cdot 1$ years for men (Bundesministerium für Gesundheit, 1990). For the same time-period in West Germany it was 79.2 years for women and 72.6 years for men (World Health Organization, 1991). This was due not just to differences in infant mortality; the difference in life expectancy was, in fact, equally great for 45 year olds in both Germanys in 1985; 32.4 years for 45 -year-old East German women and 35.2 years for West German women of the same age. This almost 3 year difference can be explained in terms of differing risks of specific diseases, largely the cardiovascular diseases. 
Ischaemic heart disease

$\rightarrow$ Lung cancer

$\rightarrow$ Liver cirrhosis

$\rightarrow$ Other heart diseases

$\rightarrow$ Cerebrovascular disease

$\rightarrow$ Colon cancer

Suicide

$\rightarrow$ Stomach cancer

$\rightarrow$ Alcohol dependency

Lymph, haem cancer

$\rightarrow$ Cancer of oesophagus

$\rightarrow$ Cancer of pancreas

Kidney cancer

Motor vehicle accident

Diseases of nervous system

$\rightarrow$ Diabetes mellitus

$\rightarrow$ Arteriosclerosis

$\rightarrow$ Hypertension

$\rightarrow$ Breast cancer

$\rightarrow$ Ischaemic heart disease

$\rightarrow$ Colon cancer

$\rightarrow$ Liver cirrhosis

Cerebrovascular disease

Ovarian cancer

Other heart diseases

$\rightarrow$ Lung cancer

Suicide

Lymph, haem cancer

Cancer of the uterus

$\rightarrow$ Stomach cancer

$\rightarrow$ Cancer of pancreas

Disease of nervous system

$\rightarrow$ Diabetes mellitur

$\rightarrow$ Hypertension
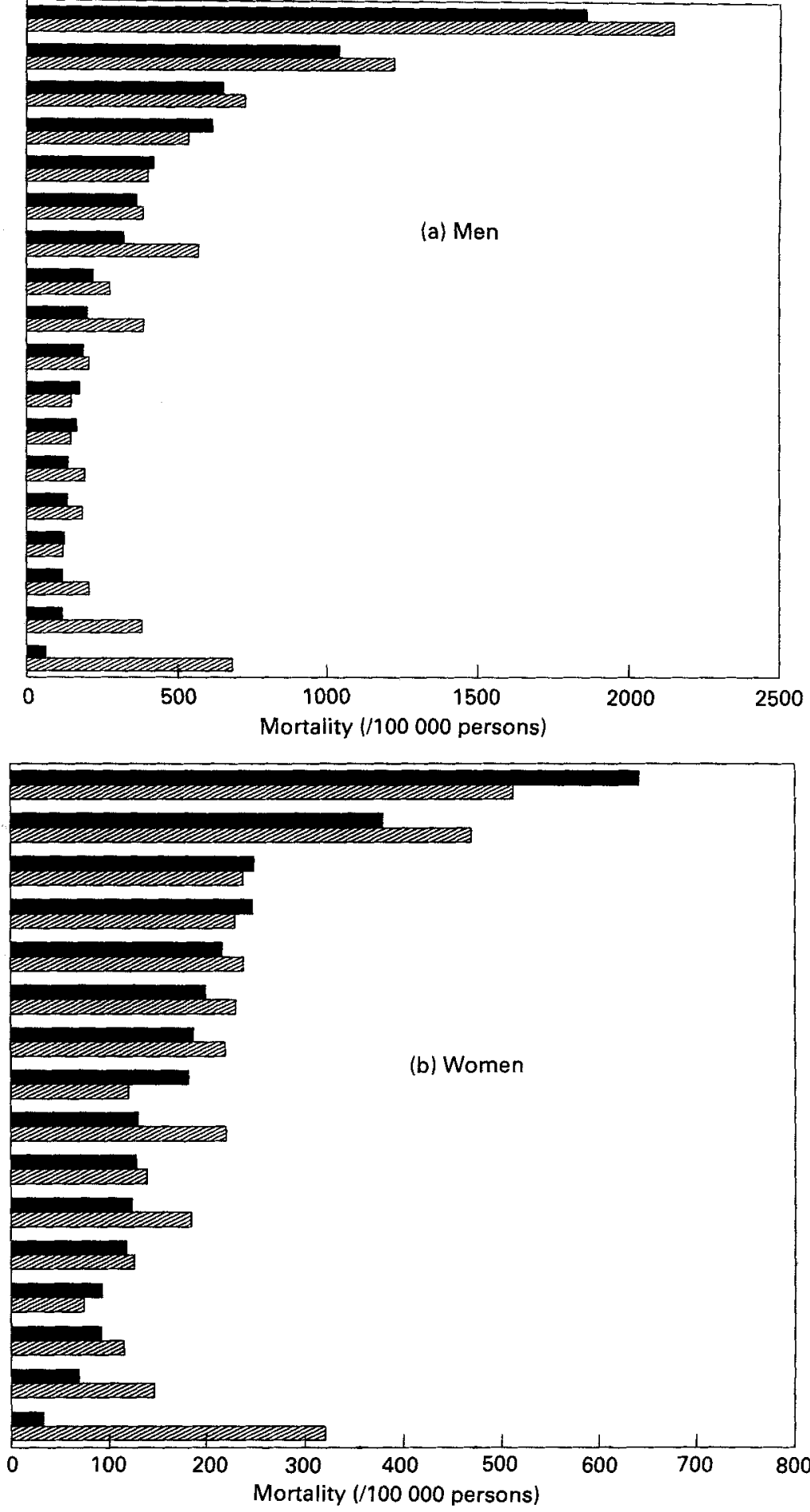

Fig. 1. The 10-year mortality risk for diseases comprising the main causes of death for 50 -year-old East and West German (a) men and (b) women are presented for 1989. $(\rightarrow$ ), Diseases considered to be related to nutritional factors; (घ), West Germany (9456 men, 4422 women); (田), East Germany (12 318 men, 5663 women). Data from Statistical Offices of the former West and East Germanys. 


\section{PREMATURE MORTALITY}

Premature mortality can be seen as any deaths before the current life expectancies, or more conservatively, all mortality before the age of 65 years. An examination of the 10-year risk of death for 50-year-old men and women in East and West Germany provides answers to the questions of who was healthier (Fig. 1(a,b)). With 10-year mortality rates of 9500 per 100000 for 50-year-old West German men and 12300 per 100000 for their East German peers, West Germans had lower total mortality rates than their age peers in the East before 1989 . This $28 \%$ difference is consistent from 30 to 50 year olds.

Thirteen of the eighteen greatest risks of death in men and eleven of sixteen in women are of nutritionally-related origin. Cardiovascular diseases contribute most to premature mortality in both male populations. Lung cancer and liver cirrhosis deaths are the second- and third-most-important causes of premature deaths among 50 year olds in both sectors, although the rates for each of these were greater among the East Germans (Fig. $1(\mathrm{a})$ ). For women, for risks which are less than half as great, a different pattern emerges. Breast cancer mortality is greater in the West German women, as are numerous other cancers (Fig. 1(b)).

\section{NUTRITION-RELATED DISEASES}

Of the many nutrition-related diseases illustrated in Fig. 1 (a and b), the two major groups i.e. cardiovascular disease and cancer, are of greatest consequence. Without a doubt, one of the major contributors to the differences in premature mortality in East and West Germany is cardiovascular disease. This holds true for all adults and for both men and women. Dietary factors are suspected of being the cause, with high intakes of saturated fat, and poor antioxidant status. Differences in body-weight, serum cholesterol levels, and hypertension are, as expected, in general less favourable among East Germans than their West German counterparts.

Contrary to expectations, cancers of all kinds are not greater in East Germany as compared with West Germany. Comparisons of cancer registry data and mortality data provide a coherent picture. The incidence of almost all cancers of the gastrointestinal tract were $30-280 \%$ higher in the East, as seen in Table 1 . The few cancers for which a greater risk was seen in the East are gall bladder, liver, uterine and pancreas. Breast cancer, which is suspected to have a nutritional aetiology was lower in the East, despite higher body-weight, and greater fat consumption. The earlier age at child birth in the East, may be an explanatory factor.

\section{RISK FACTOR STATUS}

The information base of mortality statistics is much stronger than that needed for risk factor comparisons. The information used here is drawn from a rough comparison of the Monica study conducted in East Germany in 1983-85, with the information from the national representative health survey, conducted in the former West Germany in 1984-86 (Bormann et al. 1991). From these sources it appears that body mass indices are, on average, greater in women from the East, a difference of about $0.6 \mathrm{~kg} / \mathrm{m}^{2}$. The prevalence of obesity, defined as a body mass index greater than 30 was significantly greater in East German women of all ages. This was not the case with East German men 
Table 1. Comparison of cancer incidences (1985-87) and mortality (1989) between East and West Germany*

\begin{tabular}{|c|c|c|c|c|c|}
\hline \multirow[b]{3}{*}{$\mathrm{ICD}$} & \multirow[b]{3}{*}{ Type of cancer } & \multirow{2}{*}{\multicolumn{2}{|c|}{$\begin{array}{l}\text { Incidence in Saarland: } \\
\text { incidence in East Germany }\end{array}$}} & \multirow{2}{*}{\multicolumn{2}{|c|}{$\frac{\text { Mortality }}{\text { West Germany:East Germany }}$}} \\
\hline & & & & & \\
\hline & & Male & Female & Male & Female \\
\hline $140-149$ & $\begin{array}{l}\text { Tongue, lip, oral cavity } \\
\text { and pharynx }\end{array}$ & 2.79 & 1.68 & $1 \cdot 30$ & $1 \cdot 00$ \\
\hline 150 & Oesophagus & 1.46 & $1 \cdot 33$ & $1 \cdot 26$ & $1 \cdot 17$ \\
\hline 151 & Stomach & 0.89 & $1 \cdot 01$ & 0.87 & 0.94 \\
\hline 153 & Colon & 1.64 & 1.46 & 1.69 & 1.51 \\
\hline 154 & Rectum & 1.09 & 0.92 & 0.71 & 0.61 \\
\hline $174-175$ & Breast & - & $1 \cdot 15$ & - & $1 \cdot 30$ \\
\hline $140-208$ & All sites except 173 & $1 \cdot 22$ & 1.02 & 1.07 & 1.05 \\
\hline
\end{tabular}

* The calculations are based on the standard world population distribution (Muir et al. 1987) and the mid-year population of Saarland for the years 1985-87. The data were provided by the 'Dachdokumentation Krebs' working group, Institute for Social Medicine and Epidemiology, Bundesgesundheitsamt. ICD, International Classification of Diseases.

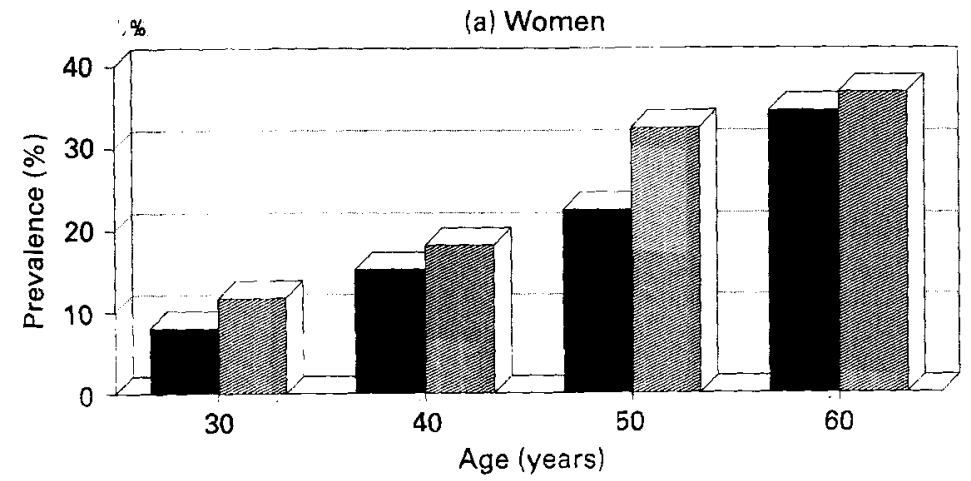

(b) Men

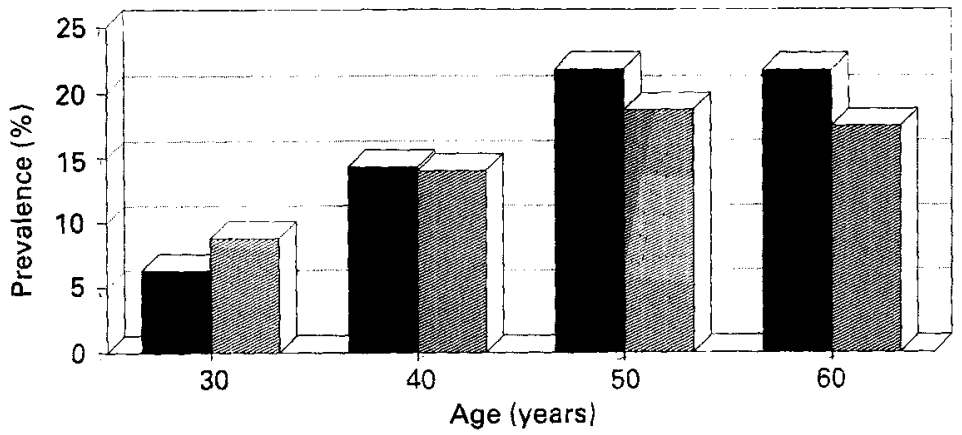

Fig. 2. Prevalence of obesity (body mass index $>30 \mathrm{~kg} / \mathrm{m}^{2}$ ) in German (a) women and (b) men. (a), West Germany; (ख), East Germany. The data are based on a representative population study conducted in West Germany in 1985 and the findings of the participants of the East German MONICA study. 
(a) Men

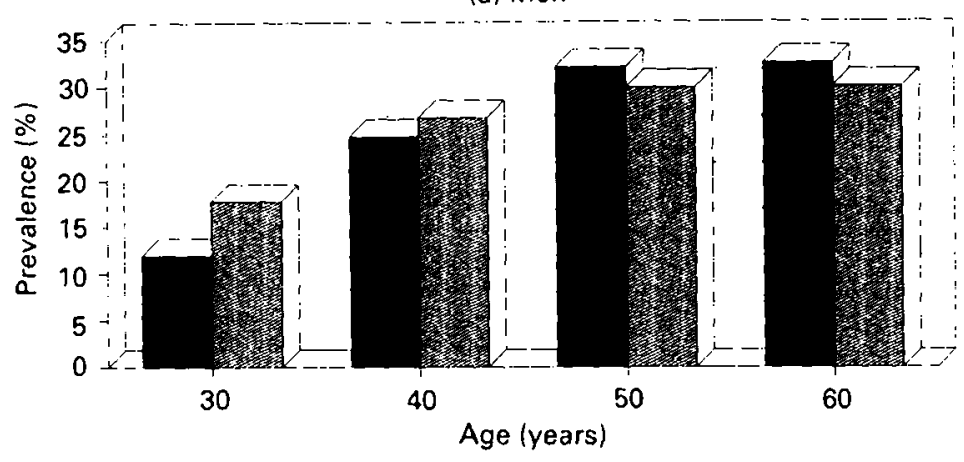

(b) Women

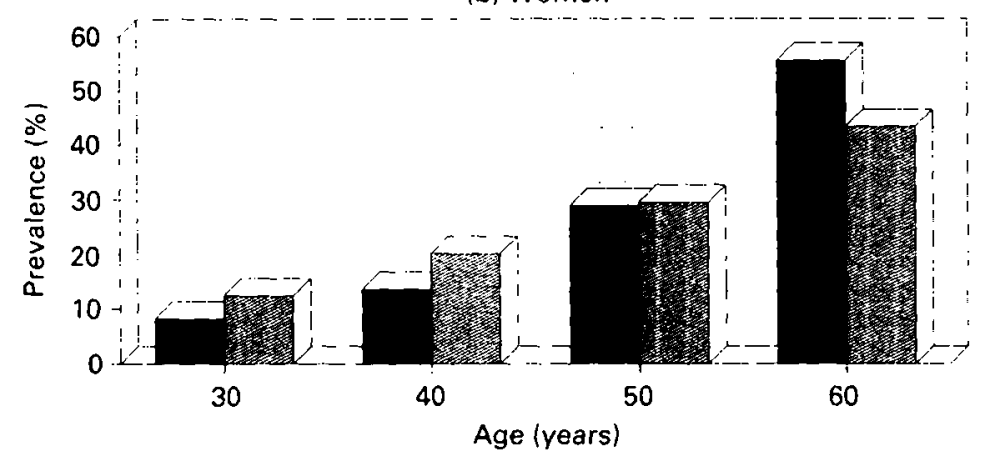

Fig. 3. The prevalence of hypercholesterolaemia (serum cholesterol $>2600 \mathrm{mg} / \mathrm{l}$ ) in German (a) men and (b) women. ( $[\mathrm{C})$, West German; (Z), East German. Hypercholesterolacmia is most prevalent in West German men over 50 years of age. Among the young adults, East German women and men show a greater tendency for elevated cholesterol. The data are based on a representative population study conducted in West Germany in 1985 and the findings of the participants of the East German MONICA study.

(Fig. 2(a, b)). West German men on the other hand are, on average, heavier after the age of 40 years (Lang et al. 1990).

Serum cholesterol levels (this is the least comparable data since independent laboratories ran the analyses, and no direct standardization was conducted) appear to be greater in East German men and women under the age of 50 years, after which the trend reverses (Fig. 3(a,b)). Roughly one-quarter of the populations in both countries had serum cholesterol levels above $2600 \mathrm{mg} / \mathrm{l}$ (Lang et al. 1990).

The prevalence of hypertension is significantly greater in all age-groups in male and female East Germans (Bormann et al. 1991).

\section{EATING BEHAVIOUR}

Information on food consumption is limited to food disappearance data from food balance sheets. This source allows only weak inference of population consumption patterns since they do not consider food eaten away from home, waste, private production of food, and exports and imports which are not monitored (Kelly et al. 1991). 


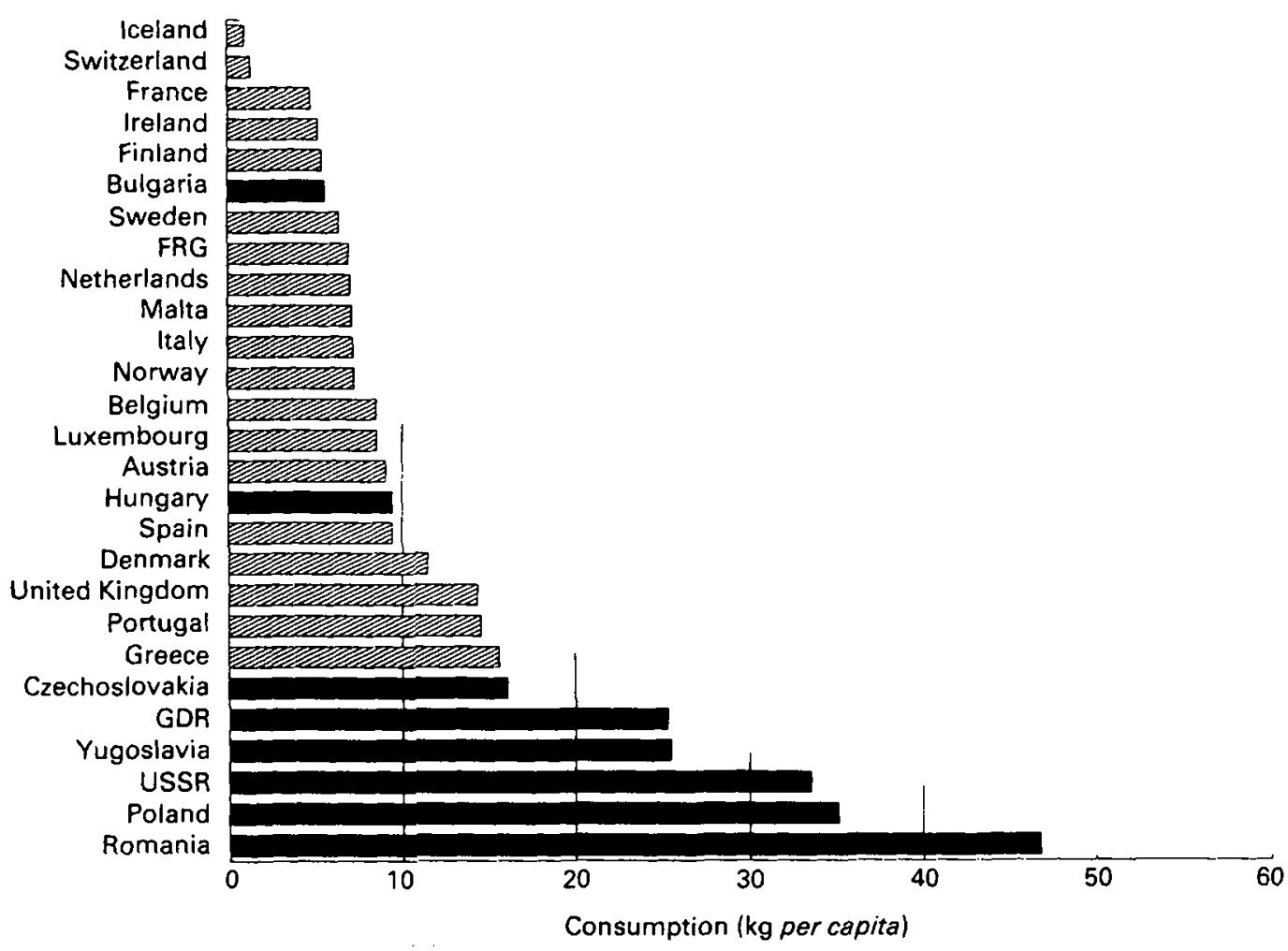

Fig. 4. Cabbage consumption in 1987 (World Health Organization, 1990). Among the factors which $\mathrm{m} f$ explain the unexpected low incidence of nutritionally related cancers in East Germany, as compared with West Germany, cabbage consumption may play a role. These per capita statistics on national intakes are based on Food and Agriculture Organization food balance sheets as presented by the World Health Organization (1990) software program on food and disease.

As weak as they are, they are the single source of data available (and are to a degree comparable) on which past intakes can be calculated. A brief examination of the per capita intakes of some staples across Europe, data of 1987 (World Health Organization, 1990), does give an impression of the inequalities, and the previous nutritional profiles, in the East and West.

With few exceptions, Eastern Europe was not deprived of a high animal-fat consumption, in many cases exceeding that of the UK by $70 \%$. Meat disappearance data were similar, if the information reported was correct, $60 \mathrm{~kg}$ per capita per year was the standard. The Eastern bloc distinguished itself in that this was largely pork, with absolute intakes averaging $40 \mathrm{~kg}$ per capita. In 1987 both Germanys were at the top of the list in pork consumption.

Wheat use also appeared considerably higher in the East, if these statistics do not simply reflect greater wastage, and less efficient distribution.

The availability of milk and dairy products (excluding butter) was for the most part lower, with seven of the Eastern countries falling in the lower half of the distribution. A clear exception here is East Germany, which with $260 \mathrm{~kg} /$ person per year surpassed West Germany by some $20 \mathrm{~kg} /$ person. The statistics may, however, be an artifact of over-reporting, to enhance the country's international image. 


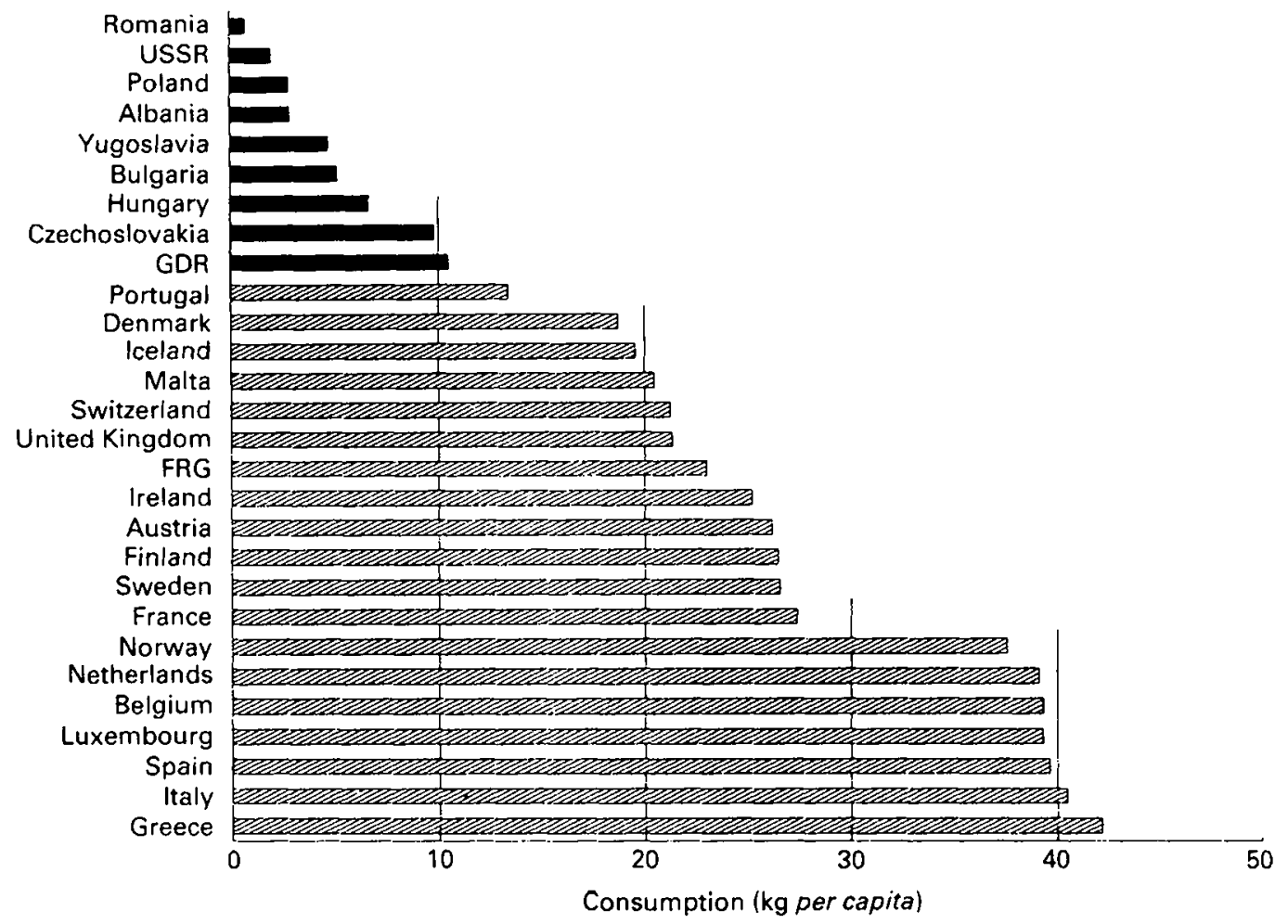

Fig. 5. Citrus fruit consumption in 1987 (World Health Organization, 1990). Citrus fruit intakes were extremely low throughout Eastern Europe. The intakes in West Germany were more than double those of East Germany. These per capita statistics on national intakes are based on Food and Agriculture Organization food balance sheets as presented by the World Health Organization (1990) software program on food and disease.

Potato use was not typically Eastern European, but it is a strong part of the German heritage. East Germany surpasses Ireland and the UK with per capita consumption of $155 \mathrm{~kg} /$ person per $\mathrm{d}$. That is double the mean consumption in West Germany.

Cabbage is a vegetable which well discriminates East from West. A two to three times greater disappearance as compared with the UK's $14 \mathrm{~kg}$ per capita per year is documented (Fig. 4). Another excellent discriminator is of course citrus fruits, with availability of less than $10 \mathrm{~kg}$ per capita per year for a commodity which is well measured since internal production is almost non-existent, waste is inconsequential, and the product is not used for feeding pets (Fig. 5).

Mean alcohol intakes also differ between countries, with lower intakes in the East, especially among women. This difference is largely due to lower wine consumption. The quantity of beer consumed was comparable. Consumption of highly concentrated alcohol (spirits) was greater in the East.

In summary it can be said that Eastern Europe was subsisting on diets quite different from those in the West, and a trend towards a more Western diet can be expected.

\section{THE FUTURE}

Without good information on the past, it is difficult to predict the future. Clearly, the merger of the East and West Germanys is resulting in a westernization of the East rather 
than an easternization of the West. East Germans are trying to adopt a West German life style as rapidly as possible.

In the short term, unemployment, reduced buying power, deteriorating living standards and increasing gaps between social classes can be expected to affect health. After the economy stabilizes it can be expected that new markets will open up. Individualism will play a strong role in life-style choices, especially in food and alcohol consumption and eating behaviour. The population will want more information and more education. Economic considerations can be expected to play a significant role in the selection of foods, and the future nutritional status of the country as a wholc (Makara, 1991). Therefore, advanced training of multipliers in nutrition should be a current priority. Furthermore, a close monitoring of developments will require better tools of nutritional surveillance than currently available. This applies not only to the situation in Germany, but also to Europe as a whole.

\section{REFERENCES}

Arab. L. (1988). Analyses, presentation, and interpretation of results. In Manual on Methodology for Food Consumption Studies, pp. 145-169. [M. Cameron and W. van Staveren, editors]. Oxford: Oxford Medical Publications.

Bormann, C., Heinemann, L. \& Hoehz, J. (1991). Kardiovaskuläre Risiken in Deutschland-Ost und-West. Müchen: Infratest Gesundheitsforschung.

Bundesministerium für Gesundheit (1990). Das Gesundheitswesen: Jahresgesundheitsbericht 1989 fiur das Gebier der ehemaligen $D D R$. Berlin: Ärztebuch Verlag GmbH.

Flores, M. \& Nelson, M. (1988). Methods for data collection at houschold or institutional level. In Manual on Methodology for Food Consumption Studies, pp. 33-106 [M. Cameron and W. van Staveren, editors]. Oxford: Oxford Medical Publications.

Kelly, A., Becker, W. \& Helsing, E. (1991). Food Balance Sheets in Food and Health Data: their use in Nutrition Policy Making. WHO Regional Publications, European Series no. 34 [E. Helsing, editor]. Copenhagen: WHO.

Kohlmeier, L., Helsing, E., Kelly, A., Moreiros-Varela, O., Trichopolou, A.. Woteki, C. E., Buss, D. H., Callmer, E., Hermus, R. J. J. \& Snajd, J. (1990). Nutritional surveillance as the backbone of national nutrition policy: Recommendations of the IUNS Committee on nutritional surveillance and programme evaluation in developed countries. European Journal of Clinical Nutrition 44, 771-781.

Lang, H.-P., Thiel, C. \& Kohlmeier, L. (1990). Daten zu Mortalität, Risikofaktoren koronarer Herzerkrankungen und zum Ernährungsverhalten. Bundesgesundheitsblatt 33, 595-6600.

Makara. P. (1991). Dilemmas of health promotion and political changes in Eastern Europe. Health Promotion International F6, 41-47.

Muir, C., Waterhouse, J., Mack, T., Powell, J. \& Whelan, S. L. (1987). Cancer incidence in five continents. International Agency for Research on Cancer no. 88. Lyon: IARC Scientific Publications.

Paul, A. A. \& Southgate, D. A. T. (1978). Conversion into Nutrients. In Manual on Methodology for Food Consumption Studies, pp. 121-144 (M. E. Cameron and W. A. van Staveren, editors]. Oxford: Oxford Medical Publications.

Percy, C. \& Muir, C. (1989). The international comparability of cancer mortality data. American Journal of Epidemiology 129, 934-946.

World Health Organization (1990). Food and Health Indicators in Europe. Copenhagen: WHO.

World Health Organization (1991). World Statistics Annual 1990. Gencva: WHO.

World Health Organization/UNEP. (1991). Sundsvall Statement on Supportive Environments (1991), Sweden. Copenhagen: WHO. 